\title{
Incidental Vocabulary Learning Through Information-Loaded and Negotiation-Oriented Tasks
}

\author{
Roya Khoii (Corresponding author) \\ Islamic Azad University, Tehran North Branch, Tehran, Iran \\ E-mail: roya_kh@yahoo.com \\ Somaye Ashuri \\ Islamic Azad University, Tehran North Branch, Tehran, Iran \\ E-mail: somaye.ashuri@gmail.com
}

Received: 06-08-2016

Published: 10-12-2016
Accepted: 08-10-2016

doi:10.7575/aiac.ijalel.v.5n.7p.30
Advance Access Published: November 2016

URL: http://dx.doi.org/10.7575/aiac.ijalel.v.5n.7p.30

\begin{abstract}
The present study aimed to investigate the effects of implementing two innovative speaking tasks, namely, informationloaded and negotiation-oriented tasks, on the incidental vocabulary acquisition of advanced Iranian EFL learners. To this end, an experimental research was conducted in an English language institute with 30 homogeneous advanced EFL learners randomly divided into two experimental groups. Experimental group I performed some information-loaded tasks using thirty five texts as speaking aids for implementing multicultural experiences, and experimental group II performed some negotiation-oriented tasks utilizing seven argumentative sentences for each topic to promote divergent thinking processes. At the end of the treatment, a vocabulary post-test and a questionnaire were administered to measure the effects of the treatments on the students' incidental vocabulary knowledge and attitude to the performed tasks in each group. The statistical analysis of the data revealed that the information-loaded tasks group had significantly outperformed the negotiation-oriented tasks group on the vocabulary post-test and had a significantly more positive attitude to the tasks they performed in their class. This study offers some implications for the development of a sizable and profound knowledge of vocabulary in an effortless and pleasant manner. It also fulfils the need of EFL teachers and material developers in their search for some effective activities and techniques that can help to improve EFL learners' incidental vocabulary knowledge.
\end{abstract}

Keywords: Incidental vocabulary learning; Information-gap tasks; Information-loaded tasks; Negotiation-oriented tasks; Opinion-gap tasks

\section{Introduction}

In the past, research in language pedagogy devoted less attention to vocabulary than to other aspects of language as a communication system. One of the reasons for this plight might have been the preference for closed systems which could be explained by rules. However, presently, great attention is given to vocabulary as a key component in L2 learning for successful communication (Chacón-Beltrán et al., 2010). It is now believed that words function as the building blocks from which learners start their second or foreign language acquisition (Restrepo Ramos, 2015). Moreover, a large vocabulary opens the door to a wider range of reading materials (Tuan, 2011), and as students develop greater fluency and expression in English, it is significant for them to attain more productive vocabulary knowledge. However, it has been frequently acknowledged that vocabulary learning is a gradual process with incremental gains occurring through repeated encounters with unknown or partially known words (Webb \& Chang, 2015, p. 2).

Methods of learning words with or without deliberate attempts are known as intentional versus incidental learning in vocabulary studies (Ting Hung, 2015, p. 107). While each approach has its own pros and cons, the proponents of the communicative approach generally advocate incidental vocabulary acquisition as they believe that explicit teaching occurs in very limited contexts and does not usually provide learners with sufficient information regarding the communicative efficiency of words (Tang \& Nesi, 2003). Similarly, they argue that learners cannot acquire a large, native-like lexicon by explicit learning methods because opportunities for explicit teaching are too few (p.67). However, learners of English as a foreign language need extra support in order for incidental learning to occur. This is because foreign language learners do not usually have enough contact with the language, on the one hand, and enough contact with the language which is at the right level for them, on the other hand, for incidental learning to occur (Nation, 2013). Schmitt (2008) suggests that influential vocabulary learning programs need to cover both an explicit and intentional learning component and a component based on increasing exposure and incidental acquisition. 
Many specialists in language teaching believe that effective vocabulary learning takes place when the learners are actively involved in the process of learning. To achieve this goal, some methods such as task-based language teaching have been innovated to help foreign language students expand their word repertoire. According to Nunan (1989), taskbased instruction is an approach which consists of a set of communicative tasks and a way to involve learners in comprehending, manipulating, producing, and interacting in the target language. In a task-based approach to learning, learners will often meet new vocabulary "in passing" as they pursue communicative goals (Newton, 2001).

While there is a large body of research on language learning through tasks and through incidental vocabulary learning, research into incidental vocabulary learning through discussion tasks has been relatively scarce. Learners will often meet unfamiliar words in communication tasks as well as in spoken input from other learners during group work. This makes the communication task a potentially valuable source of opportunities for incidental vocabulary learning (Newton, 2013). Moreover, producing output provides learners with some opportunities for hypothesis testing. In other words, when conversing with others, they may try out various ways of saying the same thing and may check whether their utterances are comprehensible and well-structured. However, when learners cannot convey their intended meanings, they may search in their already existing linguistic repertoire to find some solutions to the problem at hand. In case they fail to find a solution therein, they might ask for assistance from others or pay more attention to the upcoming input. Another function of output is the metalinguistic function; that is, output may encourage learners to consciously think about the language and focus on what they wish to say or not to say (Nassaji \& Tian, 2010). Therefore, the present study aimed to make a contribution in this regard by implementing information-loaded and negotiation-oriented tasks as two subcategories of speaking tasks in the classroom to investigate their effects on the incidental vocabulary acquisition of Iranian advanced EFL learners.

\section{Review of the related literature}

\subsection{Incidental Vocabulary Acquisition}

According to Zeeland and Schmitt, "Incidental learning occurs when learners acquire new aspects of their L2 without being focused on doing so" (2013, p.609), and it is contrasted with intentional vocabulary learning defined as "any activity geared at committing lexical information to memory" (Rieder, 2003). Unlike intentional learning, incidental learning appears in both abstract and factual knowledge, while intentional learning can be applied only to factual knowledge. In this process, vocabulary learning occurs in context through extensive reading, listening to radio, stories, music, watching television, movies and conversations (Hunt \& Beglar, 2005; Tuan, 2011). On the other hand, explicit vocabulary learning can happen deliberately by memorizing thousands of words along with grammatical rules (Hulstijn \& Laufer, 2001). However, as Gass (1999) notes, if we define incidental vocabulary acquisition as the 'side-effect' of another activity, we are in fact neglecting the active role that language learners play in this process. The fact that learning occurs as a by-product of reading does not automatically indicate that it does not involve any conscious processes.

A typical and well-known supporter of incidental vocabulary learning is Krashen (1989), who, in the context of his input hypothesis, argues that we acquire vocabulary and spelling through exposure to comprehensible input. While acknowledging the invaluable role comprehensible input serves in SLA, Swain (1985) argues that it is not sufficient for L2 learners to fully develop their L2 proficiency. She emphasizes that what these learners need is not only comprehensible input but also comprehensible output (1985). The construct holds that when learners run into communication difficulties, they try to make their output more coherent, appropriate, and precise. This is assumed to contribute to language learning by making learners notice the gap between their interlanguage and the second language as it is used by native speakers and discover what they can do and cannot do (Tarone, 2014).

\subsection{Task-Based Language Teaching}

It is generally argued that task-based language teaching (TBLT) involves production-based tasks. For example, Swain (2005) criticized TBLT for its focus on 'pushed output' and its failure to provide opportunities for foreign language learners to acquire 'new linguistic material'. Her criticism seems to rely on the assumption that tasks need to involve both interaction and production. This assumption is perhaps justified because the majority of the studies that have investigated tasks have focused on learner production. However, as Ellis (2009, cited in Shintani, 2012) has pointed out, tasks can also be 'input-based'. Such tasks can be designed in a way to provide the required opportunities for learning the 'new linguistic material' that Swain considers to be necessary.

Read (2004) notes that it would be effective for teachers to introduce target vocabulary items to students through tasks and ask them to read only the texts including those target words. Teaching tasks should help learners use the language to express meaning because they genuinely wish to communicate something to achieve a particular goal. Linguistic regularities are acquired by means of 'noticing' while performing communicative activities and should, consequently, be described by incidental 'focus on form' during task performance (Swain, 2005). This might require the students to express their own ideas and opinions, express a wish or a desire to do some activity, negotiate and solve a specific problem, or create and maintain social relationships and friendships. To achieve such purposes, there is a need to activate a range of appropriate expressions (McDonough et al., 2013).

A number of studies have investigated the effects of different task types on vocabulary learning. Newton (2013) investigated the ways in which two groups of four adult EFL learners responded to unfamiliar words that they were exposed to in four communication tasks and the effects of different engagement levels with these words (including negotiation of form and meaning) on their later recall of word meaning. Of the four tasks, two were information gap 
tasks and two were opinion gap tasks. The results revealed a significant task type effect on not only the amount but also the type of negotiation, with more negotiation of word form in the information gap tasks versus more negotiation of meaning in the opinion gap tasks. He concluded that, while the learners had also shown improved recall of several words that had not been negotiated, the ones which had been negotiated would be more likely to be acquired.

Nassaji and Tian (2010) examined and compared the effectiveness of two types of output task (reconstruction cloze and reconstruction editing tasks) for learning English phrasal verbs in two intact low-intermediate adult EFL classes. They also investigated whether doing the tasks collaboratively led to greater success in learning the target verbs, and also whether task type made a difference. The results showed that performing the tasks collaboratively (in pairs) as opposed to individually led to greater accuracy in task completion. Nevertheless, collaborative tasks did not lead to significantly greater gains in vocabulary knowledge than individual tasks. Here, an effect was observed for task type, with editing tasks being more effective than cloze tasks, in promoting negotiation and learning.

Karimi (2010) examined the effectiveness of information-gap tasks in promoting Iranian EFL learners' vocabulary knowledge and concluded that adopting the information gap task was useful in the enhancement of students' word knowledge. In the same vain, Vosoughi and Mehdipour (2013) explored the effects of implementing two types of production and recognition tasks on incidental vocabulary learning of 40 advanced Iranian EFL learners divided in two experimental groups. They concluded that the production group had outperformed the recognition group with regard to incidental vocabulary learning.

Although the above studies differ in terms of the employed task type and, perhaps, theoretical orientations, all of them confirm the significant role of tasks in vocabulary acquisition. Nevertheless, there are few studies on exploring the effects of different kinds of oral tasks in improving incidental vocabulary acquisition, which prompted the researchers to carry out the present study. It is worth mentioning that, to the best of the researchers' knowledge, the two speaking tasks, information-loaded and negotiation-oriented tasks, used here are completely new to research in the field of incidental vocabulary learning.

\subsection{Information-Loaded Tasks}

In the present study, information-loaded tasks are defined by the researchers as a subcategory of information-gap tasks which provide learners with interesting facts through multicultural experiences. An 'information-gap activity' requires students to use the language to exchange some information and get their meaning across. It makes students accomplish a task through using the language while concentrating on meaning and not on the structure of the language. (Ellis, 2003; Ur, 1996). When performing such tasks, EFL students use their English language skills to share information in order to complete the assigned task. At first, they might not be able to complete the task with the information they have; however, in the course of the activity, they interact to exchange information for a real purpose, which is exactly why people use language in authentic contexts. The students do not merely repeat their teacher's phrases and sentences, nor do they ask questions whose answers are already known to them. Instead, they ask their own questions, give commands, and exchange information that is new to them (Ellis, 2003).

As specified by Pica (2005), the information-gap task has several characteristics: only one outcome or answer is considered to be possible, appropriate, or correct and, in order to reach this answer, the task participants need to have a verbal exchange of information. To attain the intended outcomes that such tasks require, the exchanged information must be both accurate and well-understood. When it becomes difficult to access one participant's information, another one signals the need for clarification, and the first participant may respond by recoding, rephrasing, or expanding the given information. This task is usually continued until the response appears to be understood. "As the participants engage in this negotiation, they draw attention to the meaning of the information and the form in which it is encoded" (Pica, 2005, p. 341).

The distinctive feature of information-loaded tasks is the use of multicultural experiences. "All direct and indirect experiences of encountering or interacting with the elements and/or members of foreign cultures are considered as multicultural experiences" (Leung et al., 2008). Such exposures to different cultures provide access to diverse ideas, promote openness to new perspectives, and help people connect seemingly disparate ideas to create new ones (Chua, 2015, p.6). Chiu and Hong (2005) argue that multicultural experiences are at the service of increasing language learners' sensitivity to knowledge and ideas in other cultures. For instance, one's social network can be a typical source of multicultural experience (Carter, 2007). Networks provide concurrent access to multiple perspectives; therefore, the different views of members of one's network become especially salient (Chua, 2015). This attitude by itself increases students' interest in adopting ideas, concepts, and insights from other cultures when performing new language tasks in an EFL class.

\subsection{Negotiation-Oriented Tasks}

In the present study, negotiation-oriented tasks are defined by the researchers as a subcategory of opinion-gap tasks. The communicative potential of these tasks is based on divergent thinking. An opinion-gap activity requires that students go beyond the given information by supplying their own ideas, personal preferences, feelings, or attitudes in order to complete a task. Such tasks have proved to be successful in promoting negotiation because they persuade the students to express their own meanings and create shared meaning over an open-ended process (Ellis, 2003). They may also require L2 learners to use factual information, formulate arguments, and justify their opinions. For some topics, there may be no right or wrong responses and no reason to expect similar responses from different students or different 
groups. For example, different groups can discuss or describe a common object from different perspectives in the class with the teacher asking each group to report to the rest of the class at the end of the task (Nunan, 2004).

The distinctive feature of negotiation-oriented tasks is the use of divergent thinking, which is an important cognitive process associated with future creative achievement. Nevertheless, what is required for creative achievement to occur is not only the ability to produce divergent ideas but also the ability to distinguish useful or most appropriate ideas from others in order to obtain a particular goal (Runco, 2010). This process allows people to think outside the norm and create new and interesting solutions (Robinson, 2005). When performing negotiation-oriented tasks, students arrive at unique and innovative ideas by divergent thinking processes that do not definitely compare with the conventional teaching techniques in the classroom environment. Thus each student may arrive at the correct or a new answer using an approach which is probably nonconforming to their peers (Roy and Carter, 2013).

Albert and Kormos (2004) state that, in a typical verbal divergent thinking task, people are usually required to generate unusual uses for common objects (e.g., bricks, forks), instances of common concepts (e.g., things that are round, strong, or loud), outcomes of hypothetical events (e.g., what would happen if people went blind, shrank to 12 inches tall, or became needless of sleeping), or similarities between common concepts (e.g., the ways in which milk and meat are similar to each other). Divergent thinking tasks can be considered to be a kind of fluency task owing to the fact that they assess productive abilities in response to existing constraints. However, unlike letter fluency tasks (e.g., list as many words that start with $f$ as you can) and semantic fluency tasks (e.g., list as many animals as you can), "divergent thinking tasks intend to capture the creative quality of the responses, not merely the number of responses" (Silvia et al., 2008). Additionally, the ability to produce unusual ideas might also prompt EFL learners to employ a wide range of vocabulary in order to present and explain them.

\subsection{Research Question}

To achieve the aim of this study, the following research question was proposed:

Q. To what extent does the implementation of negotiation-oriented versus information-loaded tasks affect the incidental vocabulary acquisition of advanced Iranian EFL learners?

\section{Methodology}

\subsection{Participants}

The participants of this study initially consisted of 42 advanced female EFL learners in an institute in Tehran speaking Persian as their first language. They were between 17 and 28 years old. However, after administering a standardized L2 achievement test, twelve of them were eliminated from the study.

\subsection{Instruments and materials}

In order to achieve the aims of the present study and to collect the required data, the following instruments were utilized:

1. A teacher-made achievement test consisting of 80 multiple-choice items to homogenize the participants in terms of language knowledge. The test consisted of three parts: vocabulary (30 items), grammar (30 items), and reading comprehension (20 items). All the items were selected from the participants' previous textbooks studied at the Institute.

2. A 50-item multiple-choice vocabulary pre-test in order to check the students' unfamiliarity with the target words at the beginning of the study.

3. Thirty five texts functioning as speaking aids in information-loaded tasks group. These texts were selected from various websites and tourist guide brochures on the Internet for provoking multicultural experiences in the classroom. Some of the unknown words in the texts were replaced with their equivalents with the help of an English native speaker. The main aim of controlling the vocabulary was to bring the majority of the words within the learners' vocabulary knowledge without oversimplifying the texts. As Joe (1998) states, reducing the number of unknown words in the text frees up the amount of learners' cognitive space to the message.

4. Seven argumentative (agree or disagree) sentences as discussion facilitators in negotiation-oriented tasks group. All of them were retrieved from the Internet to promote the divergent thinking process among the learners.

5. A vocabulary post-test administered at the end of the treatment to measure the incidental vocabulary knowledge of the learners. This test consisted of 30 multiple-choice vocabulary items, and the time allocated to it was 15 minutes.

6. A questionnaire used to investigate the cognitive and behavioral attitude of the participants towards the performed speaking activities. The items were adapted from the attitude questionnaire by Abidin et al. (2012) and designed based on a 5-point Likert scale from Level 1 (Strongly agree) to Level 5 (Strongly disagree).

\subsection{Procedure}

In order to carry out the research, the following steps were followed:

3.3.1 Administering the achievement test

A teacher-made achievement test was used to confirm the homogeneity of the participants in terms of English knowledge. After scoring the papers and calculating the B-indices of all test items, 10 of the 80 items were identified as being defective and eliminated from the test. The Threshold Loss Agreement Coefficient dependability of the modified achievement test was equal to 0.81 , which was satisfactory. Furthermore, given the cut-point score of 60 percent on the 
modified achievement test, 12 of the 42 participants were eliminated from the experiment, and the remaining students were equally divided into two experimental groups.

\subsubsection{Administering the vocabulary pre-test}

After administering a 50-item multiple-choice vocabulary pre-test, 30 words that were unfamiliar to all the participants were selected as the target words of the study. They consisted of eight adjectives (ultimate, reluctant, unbiased, invulnerable, hazardous, tentative, habitable, hospitable), twelve verbs (wane, procrastinate, conserve, distribute, eliminate, advocate, gamble, interfere, coincide, pamper, compensate, contaminate), and ten nouns (ramification, hierarchy, heredity, emission, gradation, genesis, spectators, stereotype, vogue, prevalence). The Threshold Loss Agreement Coefficient Formula was used to estimate the dependability of the pre-test scores $(r=0.70)$.

\subsubsection{Treatment}

During the 10-session treatment period, experimental group I performed some information-loaded tasks (creating concept maps, short-text reading, group discussions based on received data, and group data diagram creation based on the related texts) while experimental group II performed some negotiation-oriented tasks (using picture cues for idea generation, topic-based idea negotiation, agree and disagree tasks based on argumentative sentences, and expression of personal ideas in the form of individual presentation based on the given topics) under the supervision of the same teacher. Based on the topic of each session, she helped the students with expressing their ideas and comments during the information-loaded and negotiation-oriented tasks while trying not to interrupt them when they were speaking. Between four and six of the target words of the study were presented per session, and the overall time devoted to the related tasks in both experimental groups was about 50 minutes each session.

It is emphasized that in none of the groups the teacher tried to intentionally attract the attention of the students to the target words of the study. Neither was any of the groups aware of the real purpose of the study because incidental vocabulary learning occurs "when the learners are required to perform a task involving the processing of some information without being told in advance that they will be tested afterwards on their recall of the information" (Hulstijn and Laufer, 2001, p. 10).The following topics were discussed successively in both groups: gender roles, cosmetic surgery, pets, transportation, cultural differences, importance of zoos, and destruction of forests. These topics were chosen because all the learners were likely to be familiar with them.

In the information-loaded tasks group, a question was posed at the beginning of each session to create a concept map. Then five different texts about a specific topic were distributed among the learners. These texts functioned as speaking aids and provided learners with multicultural information to assist them in the process of speaking. After reading them, the students were supposed to share their received information with the whole class. In addition, they discussed the positive, negative, and interesting points of a specific theme in various countries. Finally, they used their received data to create group data diagrams.

In the negotiation-oriented tasks group, two pictures were initially shown to the students as cues for idea generation during discussion at the beginning of each session. Secondly, based on the topic of the day, the teacher wrote an argumentative sentence on the board. Following this, the learners were divided into two 'agree' and 'disagree' groups and began discussing their views. They could use some innovative, new, and imaginary ideas to support their comments. Finally, they expressed their personal ideas in the form of individual presentations.

\subsubsection{Administering the vocabulary post-test}

At the end of the treatment, a vocabulary post-test was administered to measure the incidental vocabulary knowledge of the participants. The Threshold Loss Agreement Coefficient dependability of the post-test scores was 0.87.

\subsubsection{Administering the Questionnaire}

To provide more support for the potential outcomes of this study, the attitude questionnaire was given to the participants after the post-test. The Cronbach Alpha reliability quotients of the questionnaire were $.70, .73$, and .76 for the cognitive aspect section, behavioral aspect section, and the total items, respectively.

\section{Data Analysis}

Initially, the descriptive statistics for the achievement test were computed. Given the cut-point score of 60 percent on the achievemet test, 12 of the participants were eliminated from the study.

Table 1. Descriptive Statistics of the Achievement Test

\begin{tabular}{lccccccc|c}
\hline & \multicolumn{9}{c}{ Mean } \\
& \multicolumn{9}{c}{ Statistic } & Std. & \multicolumn{2}{c}{ Std. } & \multicolumn{2}{c}{ Skewness } \\
Groups & $\mathrm{N}$ & Min. & Max. & & Error & Deviation & Statistic & Std. Error \\
\hline EX I & 15 & 45.00 & 68.00 & 54.80 & 8.33 & 8.33 & .283 & .580 \\
EX II & 15 & 45.00 & 68.00 & 55.86 & 7.32 & 7.32 & .110 & .580 \\
\hline
\end{tabular}


The results of the skewness analysis, .48 (.283/.580) for experimental group I and .18 (.110/.580) for experimental group II, confirmed the normality of the scores of both groups, as both values fell within the range of -1.96 and +1.96 ( Table 1).

In order to check the homogeneity of the variances of the two groups on the achievement test, a Levene's test was run. With $\mathrm{F}(1,28)=.379, p=.543$ (two-tailed), it was decided that there was no statistically significant difference between the variances of the two groups on the achievement test at the outset of the study. Moreover, to ensure the homogeneity of the two groups' mean scores on this test, an independent samples $t$-test was run. With $t(28)=.372, p=.712$ (twotailed), it was concluded that there was no significant difference between the means of the two experimental groups on this test before the treatment (Table 2).

Table 2. Independent Samples t-test for the Achievement Test

\begin{tabular}{|c|c|c|c|c|c|c|c|c|c|c|}
\hline & & \multicolumn{2}{|c|}{$\begin{array}{l}\text { Test for } \\
\text { Equality of } \\
\text { Variances }\end{array}$} & \multicolumn{7}{|c|}{ t-test for Equality of Means } \\
\hline & & \multirow[b]{2}{*}{$\mathrm{F}$} & \multirow[b]{2}{*}{ Sig } & \multirow[b]{2}{*}{$\mathrm{t}$} & \multirow[b]{2}{*}{ df } & \multirow{2}{*}{$\begin{array}{l}\text { Sig. (2- } \\
\text { tailed) }\end{array}$} & \multirow{2}{*}{$\begin{array}{l}\text { Mean } \\
\text { Difference }\end{array}$} & \multirow{2}{*}{$\begin{array}{l}\text { Std. Error } \\
\text { Difference }\end{array}$} & \multicolumn{2}{|c|}{$\begin{array}{l}95 \% \text { Confidence } \\
\text { Interval of the } \\
\text { Difference }\end{array}$} \\
\hline & & & & & & & & & Lower & Upper \\
\hline \multirow{2}{*}{$\begin{array}{l}\text { Achievement } \\
\text { Test } \\
\text { EX I \& EX II }\end{array}$} & $\begin{array}{l}\text { Equal } \\
\text { Variances } \\
\text { assumed } \\
\end{array}$ & .379 & .543 & .372 & 28 & .712 & 1.06 & 2.86 & 6.93 & 4.80 \\
\hline & $\begin{array}{l}\text { Equal } \\
\text { variances } \\
\text { not } \\
\text { assumed }\end{array}$ & & & .372 & 27.5 & .713 & 1.06 & 2.86 & 6.94 & 4.80 \\
\hline
\end{tabular}

At the end of the treatment, a vocabulary post-test was administered to measure the incidental vocabulary knowledge of both experimental groups. The descriptive statistics of the vocabulary post-test are shown in (Table 3).

Table 3. Descriptive statistics of the vocabulary post-test

\begin{tabular}{|c|c|c|c|c|c|c|c|c|}
\hline Groups & $\mathrm{N}$ & Min. & Max. & $\begin{array}{l}\text { Mean } \\
\text { Statistic }\end{array}$ & $\begin{array}{l}\text { Std. } \\
\text { Error }\end{array}$ & $\begin{array}{l}\text { Std. } \\
\text { Deviation }\end{array}$ & $\begin{array}{l}\text { Skewness } \\
\text { Statistic }\end{array}$ & Std. Error \\
\hline EX I & 15 & 8 & 20.00 & 15.33 & 1.04 & 4.032 & -.350 & .580 \\
\hline EX II & 15 & 5 & 15.00 & 9.60 & .882 & 3.418 & .494 & .580 \\
\hline
\end{tabular}

The results of the skewness analysis, -.60 (-.350/.580) for experimental group I and .85 (.494/.580) for experimental group II, confirmed the normality of the post-test scores of both groups, as both values fell within the range of -1.96 and +1.96 ( Table 3).

In order to check the homogeneity of the variances of the two groups on the vocabulary post-test, a Levene's test was run. With $\mathrm{F}(1,28)=.587, p=.450$ (two-tailed), it was concluded that the variances of the two groups' scores on the vocabulary post-test were homogeneous (Table 4). Moreover, with $\mathrm{t}(28)=4.373, p=.008$ (two-tailed), it was decided that there was a significant difference between the means of the two experimental groups on this test (Table 4).

Table 4. Independent Samples t-test for the Vocabulary Post-test

\begin{tabular}{|c|c|c|c|c|c|c|c|c|c|c|}
\hline & & \multicolumn{2}{|c|}{$\begin{array}{l}\text { Levene's Test } \\
\text { for Equality } \\
\text { of Variances }\end{array}$} & \multicolumn{5}{|c|}{ t-test for Equality of Means } & & \\
\hline & & \multirow[b]{2}{*}{$\mathrm{F}$} & \multirow[b]{2}{*}{ Sig } & \multirow[b]{2}{*}{$\mathrm{t}$} & \multirow[b]{2}{*}{$\mathrm{df}$} & \multirow[b]{2}{*}{$\begin{array}{l}\text { Sig. }(2- \\
\text { tailed) }\end{array}$} & \multirow[b]{2}{*}{$\begin{array}{l}\text { Mean } \\
\text { Difference }\end{array}$} & \multirow[b]{2}{*}{$\begin{array}{l}\text { Std. Error } \\
\text { Difference }\end{array}$} & \multicolumn{2}{|c|}{$\begin{array}{l}95 \% \text { Confidence } \\
\text { Interval }\end{array}$} \\
\hline & & & & & & & & & Lower & Upper \\
\hline \multirow{2}{*}{$\begin{array}{l}\text { Vocabulary } \\
\text { post-test } \\
\text { EX I \& EX } \\
\text { II }\end{array}$} & $\begin{array}{l}\text { Equal } \\
\text { Variances } \\
\text { assumed }\end{array}$ & .587 & .450 & 4.373 & 28 & .008 & 5.733 & 1.311 & 3.047 & 8.418 \\
\hline & $\begin{array}{l}\text { Equal } \\
\text { variances } \\
\text { not } \\
\text { assumed }\end{array}$ & & & 4.373 & 27.75 & .008 & 5.733 & 1.311 & 3.046 & 8.419 \\
\hline
\end{tabular}


IJALEL 5(7):30-39, 2016

Finally, a questionnaire was used to investigate the participants' attitude towards the performed speaking activities. The descriptive statistics of the students' scores to the questionnaire are given below (Table 5).

Table 5. Descriptive Statistics of the Questionnaire

\begin{tabular}{|c|c|c|c|c|c|c|}
\hline & Groups & $\mathrm{N}$ & Min & Max & \multicolumn{2}{|c|}{ Mean } \\
\hline \multirow{2}{*}{$\begin{array}{l}\text { Cognitive } \\
\text { aspect of } \\
\text { attitude }\end{array}$} & EX I & 15 & 20.00 & 45.00 & 34.06 & 6.45 \\
\hline & EX II & 15 & 15.00 & 40.00 & 26.80 & 8.91 \\
\hline \multirow{2}{*}{$\begin{array}{l}\text { Behavioral } \\
\text { aspect of } \\
\text { attitude }\end{array}$} & EX I & 15 & 12.00 & 30.00 & 23.86 & 4.77 \\
\hline & EX II & 15 & 13.00 & 26.00 & 18.73 & 3.95 \\
\hline \multirow{2}{*}{$\begin{array}{l}\text { Total } \\
\text { attitude }\end{array}$} & EX I & 15 & 30.00 & 60.00 & 45.26 & 8.24 \\
\hline & EX II & 15 & 30.00 & 50.00 & 39.53 & 6.23 \\
\hline
\end{tabular}

After checking the normality of the scores, a series of Levene's tests and t-tests were run in order to compare the variances and mean scores of the two groups with each other on the cognitive and behavioral sections of the questionnaire as well as on the total questionnaire.

Table 6. Independent Samples t-test for the Means of Scores on the Questionnaire

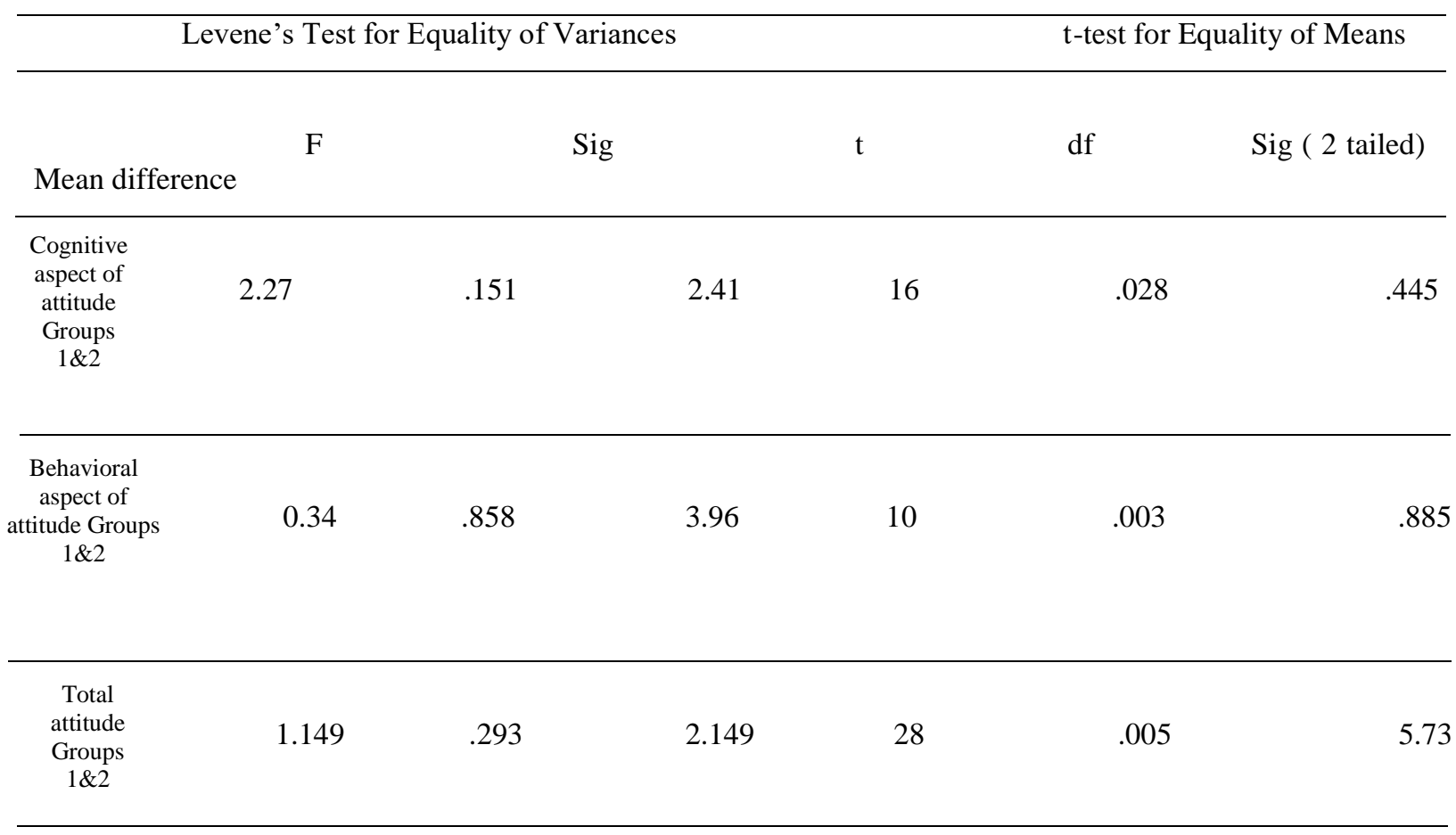

As given in Table 6 , with $\mathrm{F}(1,16)=2.27, p=.151$ (two-tailed); $\mathrm{F}(1,10)=0.34, p=.858$ (two-tailed), $\mathrm{F}(1,28)=$ $1.149, p=.293$ (two-tailed), it was concluded that the variances of the two experimental groups' cognitive scores, behavioral scores, and total scores, respectively, on the questionnaire were homogeneous. Moreover, with $\mathrm{t}(16)=2.41$, $p=.028$ (two-tailed); $\mathrm{t}(10)=3.96, p=.003$ (two-tailed), $\mathrm{t}(28)=2.149, p=.005$ (two-tailed), it was decided that there was a significant difference between the means of the two experimental groups' cognitive, behavioral, and total scores, respectively, on the questionnaire in favor of the information-loaded tasks group.

\section{Discussion}

The results of this study demonstrated that the information-loaded tasks group had significantly improved their vocabulary knowledge comparing to the negotiation-oriented tasks group. The reason for the relative success of information-gap tasks in the process of incidental vocabulary acquisition, according to Pica and Doughty (1985), might 
lie in their collaborative nature. Ample evidence suggests that collaborative tasks create more language learning and, particularly, more vocabulary learning opportunities than individual tasks (Fernández Dobao, 2014, p. 500).

The collaborative nature of the information tasks and the support participants received from each other in their efforts to complete the tasks while discussing them might have led to effective performance in this experiment. Hess (2001) confirms that information-gap activities can result in comprehensive feedback from the learners including a wide variety of opinions, references, values, and experiences. The information-gap tasks require the students to participate more actively in the process of learning, which will result in increasing their motivation to learn English much more enthusiastically (Ur, 1996). Conversely, as Prabhu (1987) points out, opinion-gap tasks might not provide the potential benefits of student-student interaction, since they demand low levels of information processing and elicit little new information in comparison with information-gap tasks. Moreover, learners might experience difficulties in expressing their own personal preferences, feelings, and attitudes during the opinion-gap tasks.

In line with the findings of this study, Karimi (2010) reports that adopting information-gap tasks is useful in enhancing the pre-intermediate EFL students' vocabulary knowledge. Fuente (2006) also maintains that information-gap tasks promote attention to form and meaning by making the processing of word meaning obligatory and are, therefore, sound pedagogical tools for the acquisition of L2 vocabulary items. Similarly, Dufficy (2005) indicates that such tasks promote communicative language use and the use of specific vocabulary in English classrooms.

In the present study, multicultural experiences, as a characteristic of information-loaded tasks, provided a more interesting environment than the divergent thinking process, as a characteristic of negotiation-oriented tasks. This might be attributed to the features of such experiences, including introducing international viewpoints, which create a thought-provoking situation to improve EFL learners' performance in the classroom (Chiu \& Hong, 2005; Chua, 2015; Chua et al., 2010). The results of this study are in tune with the claim made by Cheng and Leung (2013) and Leung et al. (2008) indicating that multicultural experiences have a positive impact on language learning.

The results of the $t$-tests for the vocabulary post-test and the attitude questionnaire of the two groups revealed that there was an agreement between the learners' attitude to the tasks employed in the class and their success in incidental vocabulary acquisition. The responses to the cognitive section of the attitude questionnaire indicated that most of the students in group I were satisfied with their performance in doing the information-loaded tasks and believed that these tasks gave them more opportunities to speak English. Similarly, with regard to their performance on the behavioral section of the questionnaire, again most of the students in information-loaded tasks group claimed that they did not worry about making mistakes during the information-loaded tasks. Nor did they feel embarrassed to speak English in front of other students. However, not a similar attitude was observed in the negotiation-oriented tasks group. Previous research also confirms that attitude toward language learning has an obvious influence on EFL students' behaviors and, consequently, on their performance (Fakeye, 2010; Kara, 2009).

\section{Conclusion}

Regardless of the discrepancies as to which task type is more beneficial than other types, there seems to be an agreement that, with respect to L2 vocabulary learning, task-based language teaching presents a valuable approach to both the research and the pedagogical perspectives of the matter worth pursuing (Fuente, 2006; Hess, 2001).The present study compared the effects of information-loaded versus negotiation-oriented tasks on EFL learners' incidental vocabulary learning. The findings testified to the superiority of information-loaded tasks in assisting foreign language in this process.

Given the students' performance on the post-test and their responses to the attitude questionnaire, the researchers concluded that implementing multicultural experiences through information-gap tasks surpasses promoting the divergent thinking process through opinion-gap tasks as regards incidental vocabulary acquisition. The use of such experiences in the context of teaching can be a way of introducing different viewpoints and ideas to language learners. As a result, they can think in innovative ways and become familiar with other cultures (Pennycook, 2007). In fact, through employing information-loaded tasks in English classrooms, teachers can create a pleasant situation for teaching and keeping their learners interested in the process of language learning.

However, the role of negotiation-oriented tasks in promoting the learners' divergent thinking process in the classroom should not be underestimated. According to Woolfolk (2009), today's world requires more divergent thinking skills than in the past due to ever-increasing technology. Moreover, new ideas by their nature do not emerge from purely linear thinking patterns (Roy \& Carter, 2013). Therefore, teachers should alter their teaching plans to address the need to foster divergent thinking among their students.

The findings of this study can be of interest to English teachers who are in search for innovative and interesting ways to improve EFL learners' vocabulary knowledge. The results of the attitude questionnaire suggest that students' realize the significance of word learning in L2 classrooms, and their preference to learn new words from friends by listening to them reveals their interest in social learning. "This may be due to the sense of freedom and collegiality students have among themselves" (Vasu \& Dhanavel, 2015 p.225).

The researchers believe that the nature of information-loaded tasks plays an important and predictable role in directing learners' attention and preference to vocabulary in productive ways. Therefore, they recommend syllabus designers to include such tasks in the materials they design for introducing, teaching, and practicing target vocabularies. Finally, the obtained results could be of importance to researchers who are interested in doing research on creating new tasks for contributing to FLLs' incidental vocabulary acquisition. 


\section{References}

Abidin, M., Pour Mohammadi, M. \& Alzwari, H. (2012). EFL students' attitudes towards learning English language: The case of Libyan secondary school students. Asian Social Science Journal, 8(2), 119-134.

Albert, A., \& Kormos, J. (2004).Creativity and narrative task performance: An Exploratory Study. Language Learning, 54, 277-310.

Carter, R. (2007). Racism and psychological and emotional injury: Recognizing and assessing race-based traumatic stress. The Counseling Psychologist, 35, 116-125.

Chiu, C., \& Hong, Y. (2005). Cultural competence: Dynamic processes. In A. Elliot \& C.A. Dweck (Eds.), Handbook of motivation and competence (pp. 489-505). New York: Guilford.

Chacón-Beltrán, R., Abello-Contesse, C., \& Torreblanca-López, M. M. (eds.). (2010). Insights into non-native vocabulary teaching and learning. Bristol: Multilingual Matters.

Chua, R.Y.J. (2015). Innovating at cultural crossroads: How multicultural social networks promote ideas flow and creativity. Singapore: Singapore Management University.

Chua, R.Y.J., Morris, M.W., \& Mor, S. (2010). Collaborating across cultures: The role of cultural metacognition and affect-based trust in creative collaboration. Working Paper. Harvard Business School.

Cheng, C., \& Leung, A. K. (2013). Revisiting the multicultural experience-creativity link: The effects of perceived cultural distance and comparison mind-set. Social Psychological and Personality Science, 4, 475-482.

Dufficy, P. (2005). Becoming in classroom talk. Prospect, 20(1), 59-81.

Ellis, R. (2003). Task-based language learning and teaching. Oxford University Press.

Fakeye, D. (2010). Students' personal variables as correlates of academic achievement in English as a second language in Nigeria. Journal of Social Sciences, 22(3), 205-211.

Fernández Dobao, A. (2014). Vocabulary learning in collaborative tasks: A comparison of pair and small group work. Language Teaching Research, 18(4) 497-520.

Fuente, M. J. (2006). Classroom L2 vocabulary acquisition: investigating the role of pedagogical tasks and formfocused instruction. Language Teaching Research, 10(3), 263-295.

Gass, S. (1999). Discussion: incidental vocabulary acquisition. Studies in Second Language Acquisition, 21, 319-333.

Hess, N. (2001). Teaching large multilevel classes. Cambridge: Cambridge University Press

Hulstijn, J. H., \& Laufer, B. (2001). Some empirical evidence for the involvement load hypothesis in vocabulary acquisition. Language Learning, 51, 539-558.

Hunt, A., \& Belgar, D. (2005). A framework for developing EFL reading vocabulary. Reading in a Foreign Language, $17,23-59$.

Joe, A. (1998). What effects do text-based tasks promoting generation have on incidental vocabulary acquisition? Applied Linguistics, 19, 357-377.

Kara, A. (2009). The effect of a learning theories unit on students' attitudes towards learning. Australian Journal of Teacher Education, 34(3), 100-113.

Karimi, F. (2010).The effect of using information-gap tasks on Iranian EFL lexical development. Retrieved from http: //eslarticle.com pub/articles/English language learning -ell/index.html

Krashen, S. (1989). We acquire vocabulary and spelling by reading: Additional evidence for the input hypothesis. The Modern Language Journal, 73, 440-464.

Leung, A. K., Maddux, W. W., Galinsky, A. D., \& Chiu, C. (2008). Multicultural experience enhances creativity: The when and how. American Psychologist, 63(3), 169-181.

McDonough, J., Shaw, C., \& Masuhara, H. (2013). Materials and methods in ELT: $A$ teacher's guide ( ${ }^{\text {rd }}$ ed.). Malden, MA: Wiley-Blackwell.

Nassaji, H., \& Tian, J. (2010).Collaborative and individual output tasks and their effects on learning English phrasal verbs. Language Teaching Research, 14 (4), 397-419.

Nation, I.S.P. (2013). Designing reading tasks to maximize vocabulary learning. Applied Research on English Language, 3(1), 1-8.

Newton, J. (2001). Options for vocabulary learning through communication tasks. ELT Journals, 55(1), 30-37.

Newton, J. (2013).Incidental vocabulary learning in classroom communication tasks. Language Teaching Research, 17(2), 164-187.

Nunan, D. (1989). Designing tasks for the communicative classroom. Cambridge: Cambridge University Press.

Nunan, D. (2004). Task-Based Language Teaching. Cambridge: Cambridge University Press.

Pennycook, A. (2007). Global Englishes and transcultural flows. London: Routledge. 
Pica, T. (2005). Classroom learning, teaching, and research: A task-based perspective. The Modern Language Journal, 3, 339-352.

Pica, T., \& Doughty, C. (1985). The role of group work in classroom second language acquisition. Studies in Second Language Acquisition, 1, 233-48.

Prabhu, N. S. (1987). Second language pedagogy. Oxford: Oxford University Press

Restrepo Ramos, F. D. (2015). Incidental vocabulary learning in second language acquisition: A literature review. PROFILE Issues in Teachers' Professional Development, 17(1), 157166. http://dx.doi.org/10.15446/profile.v17n1.43957.

Read, J. (2004). Research in teaching vocabulary. Annual Review of Applied Linguistics, 24, 146-161.

Reider. A. (2003). Implicit and explicit learning in incidental vocabulary acquisition. Views, 12, 24-39.

Robinson, K. (2005, July). The arts: A lifetime of learning. Symposium conducted at the National Forum of Education Policy, Denver, CO.

Roy, J., \& Carter, V. (2013). Elementary teacher perceptions of teaching practices that foster creative thinking in students. Inquiry, 14, 75-94.

Runco, M.A. (2010) Divergent thinking, creativity and ideation, in J.C. Kaufman and R.S. Sternberg (Eds) The Cambridge handbook of creativity. Cambridge: Cambridge University Press.

Schmitt, N. (2008). Instructed second language vocabulary learning. Language Teaching Research, 12(3), 329-369.

Shintani, N. (2012). Input-based tasks and the acquisition of vocabulary and grammar: A process-product study. Language Teaching Research, 16(2), 253-279.

Silvia, P. J., Winterstein, B. P., Willse, J. T., Barona, C. M., Cram, J. T., Hess, K. I., Martinez, J. L., \& Richard, C. A. (2008). Assessing creativity with divergent thinking tasks: Exploring the reliability and validity of new subjective scoring methods. Psychology of Aesthetics, Creativity, and the Arts, 2, 68-85.

Swain, M. (1985). Communicative competence: Some roles of comprehensible input and comprehensible output in its development. In S. Gass \& C. Madden (Eds), Input in second language acquisition, Newbury House, Rowley, Mass.

Swain, M. (2005). The output hypothesis: Theory and research. In E. Hinkel (Ed.), Handbook of research in second language, 471-483. Mahwah, NJ: Erlbaum.

Tang, E., \& Nesi, H. (2003). Teaching vocabulary in two Chinese classrooms: school children's exposure to English words in Hong Kong and Guangzhou. Language Teaching Research 7(1), 65-97.

Tarone, E. (2014). Enduring themes from the interlanguage hypothesis. In Z.-H. Han \& E. Tarone (Eds.), Interlanguage: 40 years later (pp. 7-26). Amsterdam: John Benjamins.

Ting Hung, H. (2015).Intentional vocabulary learning using digital flashcards. English Language Teaching, 8(10), 107_112.

Tuan, L. T. (2011). An empirical research on self-learning vocabulary. Theory and Practice in Language Studies, 1(12), $1688-1695$.

Ur, P. (1996). A course in language teaching: Practice and theory. Cambridge:

Vasu, S, \& Dhanavel, P.S. (2015). Understanding the attitude of ESL learners to vocabulary learning. Calidoscópio, 13, 218-226.

Vosoughi, H., \& Mehdipour, Z. (2013). Effects of recognition task and production task on incidental vocabulary learning of Iranian EFL learners. International Research Journal of Applied and Basic Sciences. 4(2), 359-363.

Webb, S., \& Chang, C.-S. (2015). How does prior word knowledge affect vocabulary learning progress in an extensive reading program? Studies in Second Language Acquisition, 1-25.

Woolfolk, A. (2009). Educational psychology (10 ${ }^{\text {th }}$ ed.). Upper Saddle River, New Jersey: Pearson.

Zeeland,H,\& Schmitt,N .(2013).Incidental vocabulary acquisition through L2 listening: A dimensions approach. System 41, 609-624. 